\title{
Using The Value Chain Model As A Method Of Prioritizing Green Reengineering Efforts
}

\author{
Laurie Schatzberg, Ph.D. \\ Don McCandless \\ Anderson School of Management \\ University of New Mexico \\ Albuquerque, NM 87131-1221
}

\author{
Vipul Kumar Gupta. Ph.D. \\ University of Texas - Pan American \\ College of Business Administration \\ University of Texas - Pan American \\ Edinburg, TX 78539-2999
}

\begin{abstract}
During the last century, humankind has advanced at an incredible rate, and, while many are focusing on profits and efficiency, the natural environment has suffered. Recently, the senior management of many companies have begun to take an interest in reducing the impact to the environment and have begun changing their business processes. While reassessing operations makes sense, finding a starting place has been a difficult. In this paper, we propose a new method of prioritizing process changes, using a synthesis of Business Process Reengineering, TQM, and Value Chain analysis. We call this framework Green Reengineering.
\end{abstract}

\section{INTRODUCTION}

Despite the spectacular gains in productivity over the last thirty years, along with the continued pursuit for improved productivity using reengineering principles, the environment has suffered tremendous environmental damage. Toothless regulation, both domestically and internationally, has been unsuccessful at stopping the harm to our environment.

In the past, the corporate world had turned a cold shoulder to being environmentally responsible, citing the fiduciary responsibility to stockholder profits as their main concern. Their sentiments reflected a perceived contradiction between corporate objectives and corporate social responsibility.

Now, the tide is changing, with current examples of both industry- and government-initiatives that aggressively protect the environment. Increasingly, environmental protection is viewed as good business, if not a corporate responsibility, and firms are introducing pro-active measures instead of simply reacting to government mandates [13, 8, 18, 4].

The next section defines Green Reengineering and presents several examples of Green Reengineering initiatives by industry and government worldwide. In Section III, readers are provided a foundation on three major enterprise change paradigms: total quality management, business process reengineering, and value chain analysis. Section IV presents our framework for prioritizing Green Reengineering opportunities; this framework has been synthesized from the paradigms reviewed in Section III. Section V presents conclusions, implications for management, and recommendations for further work in this area.

\section{GREEN REENGINEERING IN INDUSTRY AND GOVERNMENT}

Green Reengineering is a new term to describe the application of business process reengineering [10] concepts a contemporary performance measure: environmental impact. We define Green Reengineering as a pro-active redesign and radical improvement of manufacturing, packaging, and distribution processes driven by a sensitivity to the natural environment. As do all reengineering efforts, Green Reengineering initiatives challenge the underlying organizational values and culture often changing them in the process. Green Reengineering radically changes core and supporting business processes to achieve dramatic improvements in the firm's contribution to environmental quality and sustainability.

Green Reengineering fundamentally shifts corporate valuation of its outputs to customers and to the environment. In essence, the community and natural environment surrounding the corporation becomes one of its highly prized constituencies. Green Reengineering can be understood as one end-point on a continuum of choices for corporate environmental stewardship. At the reactive end of this continuum, firms choose Green Reengineering simply to comply with governmental regulations. Several examples come from the United States, Germany, and Japan. At the other end of this continuum are radical corporate initiatives in Green Reengineering wherein the health and well-being of the environment and community are ends in themselves and not merely means toward some other corporate end.

\section{A. Government Triggers for Green Reengineering}

The US government is stepping up its efforts to stop companies that are violating federal environmental laws by gathering evidence that will help the Justice Department prosecute cases [3]. In the last five years, the Environmental Protection Agency (EPA) has increased the number of agents actively pursuing violators by $134 \%$. These tough new cops are helping to enforce the criminal provisions of U.S. anti-pollution laws. Cases involving senior management were up $241 \%$ over the same time period, with prosecutions up $133 \%$.

As the number of these "Enviro-Cops" grows along with prosecutions, fines and jail time, senior management is becoming concerned for their own liability. In addition, the tough Clean Air and Clean Water Acts of the 1970's have been recently modified to include double and triple fines along with longer sentences mandated for "knowing" violations. Further, with these laws, if it can be shown that company officials should have been aware, even if another administration was responsible, present management is now liable.

The German government, both local and federal, is also aggressively protecting the environment. Local law now requires manufacturers to take back all packaging from their products and recycle it. The German Environmental Minister no longer accepts environmental cleanup as a task of the State [20]. In their agreement, retailers and manufacturers have teamed up to create the Dual Collection System. Consumers pay less than $\$ 3.00$ per month for the program. Given that the costs are nominally born by manufacturers and retailers, this program has significantly reduced packaging.

Japan, long a contender in the world wide market, has surpassed the United States in the quest for increased efficiencies. Much of their success has been due to their "eco-industrial" initiatives, underwritten by the Japanese government. Capitalizing upon this government-industry alliance, Japan has built 
the largest combined-cycle (co-generation) plant. This clean plant emits less than one-sixth of the nitrogen dioxide pollution allowed for the new U.S. plants and emits virtually no sulfur dioxide. The result is a cleaner environment and ultra efficient power generation.

Further, Japan's New Energy Development Organization actively supports new advances in solar cell development with fiscal incentives to encourage investments in energy conservation, and to create markets for new products. Several major semiconductor manufacturers have announced research and development programs aimed at eliminating the use of ozonedepleting chloroflurocarbons for cleaning semiconductors by the year 2000. Nissan is committed to eliminating freon from its air conditioners within two years. Sumimoto has developed a lightweight metal that is as strong as steel, but requires much less energy to produce. Since it is lighter weight than steel, the energy required to power the end-products made with this material is also reduced.

\section{B. Corporate Triggers for Green Reengineering}

Despite a widely held misperception that "green" means marginal profits, many companies have implemented successful, proactive reengineering strategies, that are indeed profitable. One estimate asserts that US-based companies are producing five times the pollution per dollar of revenue compared with Japanese and more than twice that of German companies [6]. Therefore, Green Reengineering can mean a significant competitive advantage and increased profits for domestic companies. Reference 14 predicts that the only companies to survive into the 21 st century are those that are able to accommodate change and that strive to create an entrepreneurial culture for their employees. In short, corporations that can and do innovate themselves and the market. Green Reengineering can be pursued within this context.

Clearly there is an immediate need for the management of companies worldwide to take responsibility for the environment. From a strategic business standpoint of increased market share and profitability, it makes good sense [13, 8]. In addition, corporations have a responsibility to society to not create an uninhabitable world [4].

Today's consumers and stockholders are beginning to hold their Boards of Directors responsible for environmental as well as financial decisions. In the US, packaging accounts for over one third of the 160 million tons of solid waste per year (or about three pounds of trash per person daily) [5, 22, 19]. While the use of environmentally friendly packaging may take a while, consumers seem willing to pay modestly higher prices for more for environmentally sound packaging [15, 17]. Clearly, the demand for greener products is increasing and will become a major factor in the coming decade as both consumers and management adopt a more long-term orientation toward conducting business [11]. McDonalds, Union Carbide, Walmart, and AT\&T all provide examples of successful Green Reengineering initiatives.

McDonalds Corporation enlisted the help of the Environmental Defense Fund, an innovative environmental research lobbying group. Besides turning a potential foe into an ally, the company received tremendous publicity along with innovative and creative new solutions to improve their efficiency. McDonalds has also replaced some of its polystyrene containers with paper, launched a polystyrene recycling program and begun using recycled paper in its napkins, towels and boxes. The positive impact on profits has been also substantial [1].
At least partly motivated by their tragic explosion in India, one organization in Union Carbide has been charged with establishing and maintaining stringent internal standards that go well beyond legal compliance. The company has also become a leader in developing technology that will lead to a $10 \%$ reduction in the world wide use of chloroflurocarbons which damages the ozone layer. Union Carbide cites an effective interface between corporate and business unit staffs that enhances communication and compliance, a high degree of employee awareness and training (culture), a strong auditing program, including "top-down" and self-assessments, and the adoption of incentives which help establish ownership of environmental liability problems by each employee. Overall, Union Carbide has emerged as a leader in environmental protection, while increasing its profits [11].

Walmart has also begun to pressure its suppliers to develop less environmentally harmful products. By using "green advertising," these new products are finding their ways onto Walmart shelves and then out of the store with consumers. Sales of green products based on this new highly profitable strategy have increased by 25 percent [21] This result is consistent with those found in the academic literature [15, 17].

Finally, AT\&T has begun to change its focus from environmental compliance to pollution prevention. By integrating design for the environment, AT\&T has been able to reduce overall waste and establish an aggressive set of goals for itself which far outweigh those required by federal and state laws. AT\&T's Columbus Works plant eliminated a harmful chemical that had been an integral part of their manufacturing process. Perchloroethylene (PCE) was eliminated within two years of implementing the plan. Overall, their manufacturing waste was reduced by $37 \%$ within five years.

\section{ENTERPRISE CHANGE: COMPARISON AND SYNTHESIS}

While the cases in Section II provide good examples of industry-initiated Green Reengineering, taken in isolation, they lack generalizability. In this section, three paradigms of enterprise change are presented as a foundation for developing a descriptive model for successful Green Reengineering efforts.

\section{A. Total Quality Management}

Total Quality Management (TQM) and its corollary, Continuous Quality Improvement (CQI) advocate incremental changes. In a TQM-driven enterprise, change typically includes stabilizing work methods, strengthening employee involvement and teamwork, heightened customer service, process benchmarking, and a commitment to continuous improvement. TQM can be highly effective for incremental and iterative improvements to a newly reengineered process.

Adopted as a firm's only enterprise change mechanism, however, the TQM techniques are insufficient to produce strategic advantages due to their focus on existing processes and modest incremental change. Further, when companies shift their focus to "quality at all costs," the bigger picture of customer satisfaction and market agility can be lost [7]. Thus, corporate missions embracing TQM can be a signal of the firm's inefficiency, since unrecoverable raw materials used in a product, such as training and quality audits, represent lost dollars and added cost [20].

\section{B. Business Process Reengineering}

Business Process Reengineering (BPR) espouses radical enterprise changes to solve problems. BPR requires fundamental 
rethinking and radical redesign of business processes to achieve dramatic improvement in critical, contemporary measures of performance [10]. BPR challenges organizational structures, work flows, job descriptions, controls, values and cultures by working to radically improve core business processes and key supporting processes [12].

The first phase of BPR requires careful articulation of management's vision of the change. During the ensuing phases, a radical redesign takes place in which all existing processes are completely reinvented, while maintaining focus on the vision and goals. Often, dramatic leaps are made in efficiency - leaps unattainable using incremental strategies or normal business process evolution. A prototype is usually developed to analyze the changes and to measure results against the initial targets.

A successful reengineering effort requires firms to shift from a traditional task or personnel focus to a process focus. Ultimately, BPR can create a kind of paradigm shift that helps the company succeed because the attitude of change becomes an ongoing part of the process [6].

Given the nature of BPR paradigm, one would expect that the majority would be cross-functional and interdepartmental in scope. On the contrary, however, a recent study suggests that BRP projects are selected on the basis of ease of implementation, instead of the likely contribution to the firm's strategic position. Moreover, projects are often restricted to a single functional area [9].

\section{Value Chain Analysis}

The ways by which one company can differentiate itself and gain market share over another can be analyzed by the Value Chain model [16]. As depicted in Figure 1, this concept calls for careful analysis of each component or process of the product (or service) creation to determine which activities add value to the customer. Defining the components of value and a means to measure it are significant tasks, and the undertaking results in management distinguishing between processes that add value and those that don't. Those that do not add value are then eliminated. This process does not result in innovative new ideas, rather it identified existing ones.

\section{GREEN RE-ENGINEERING FRAMEWORK}

Applying value chain analysis within a strategy of BPR enables management to prioritize candidate processes for reengineering. Incorporating value analysis into BPR will focus management attention upon priority area, thereby increasing the likelihood of significant payback for the effort.

By proactively redesigning their businesses, management can create new business opportunities in the form of markets for new services and products required as the firm completes its own greening strategy and for green versions of existing goods. In addition, as firms find or create new Green Reengineered products and services the firm may be able to offer products and services other companies [20], thereby creating an entirely new profit center.

A differentiation strategy based on environmental protection can add value to the product. Since many companies will adopt a "wait and see" attitude toward environmental products, there is a window of opportunity for firms whose management is prepared to exploit it. Over time, corporate greening will become so widespread, that any "green advantage" will become a competitive necessity. However, in this interim, Green Reengineering leaders will have netted more profits, production efficiencies, and customer goodwill [13].

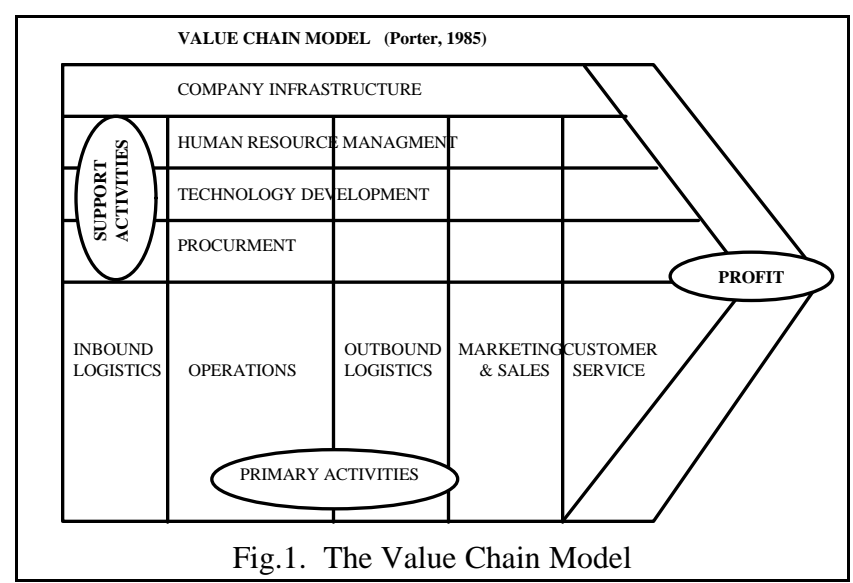

A differentiation strategy based on environmental protection can add value to the product. Since many companies will adopt a "wait and see" attitude toward environmental products, there is a window of opportunity for firms whose management is prepared to exploit it. Over time, corporate greening will become so widespread, that any "green advantage" will become a competitive necessity. However, in this interim, Green Reengineering leaders will have netted more profits, production efficiencies, and customer goodwill [13].

Coupling a value chain paradigm with BPR and TQM within the context of environmental responsibility leads to reduced waste, increased productivity, and recycling, thereby reducing the costs of good sold. The proposed framework guides management to (1) articulate the vision and goals, (2) develop new processes to achieve those goals, and (3) implement and track their success. Each of these steps is decomposed to specific tasks, yielding an implementation framework that can be utilized in most manufacturing companies to guide their Green Reengineering efforts. The framework is outlined in Figure 2, below where elements of BRP and Value Chain Analysis are synthesized.

To begin, the articulation of the green vision by a highly respected and visible champion provides the foundation for successful Green Reengineering. In concert with their responsibility for creating a green competitive advantage, the team must have the authority and resources to complete their assignment in the allowed time frame. To help guarantee success, the vision and goals (for example, improvements in quality, cost, customer service, or cycle times) for the project must be explicit and communicated clearly throughout the firm.

Management must then question the usual methods by which they conduct businesses. In this manner, methods that had seemed essential, often are revealed to be inappropriate and without value. Management learns to distinguish between value-depleting and value-adding processes. They will then identify relevant performance measures. This learning is the foundation for a sustainable competitive advantage.

From an analysis of the value-adding processes, the team will identify the inherent green opportunities, their costs and benefits, and then apply priorities. Prioritizing projects based on costs and benefit is reasonable only when the analysis is broad-based and inclusive.

Finally, the implementation of radically redesigned processes will likely require changes to both capital equipment and process controls. Beyond these physical implementation concerns, however, the reengineering team is responsible to lead the procedural and philosophical changes. Successful green systems include enterprise-wide cooperation in support of green goals 
and rationale. Further, there must be a commitment to the underlying green-knowledge acquisition process.

\section{CONCLUSION}

Despite spectacular gains in productivity over the last thirty years, the improvements have not been without serious environmental costs. Management has been focused elsewhere in their quest towards improving profitability, and societies are just finding out the true costs of corporate social irresponsibility. Green Reengineering promises to enable companies not only to re-think their manufacturing processes, but to emerge as successful competitors, despite the seemingly hostile changes occurring in the business environment. Indeed, many companies have already proven that it is possible to find profit in environmentally motivated reengineering initiatives.

Green Reengineering has been conceived by synthesizing concepts from BPR, TQM and Value Chain analysis. In focusing management on reengineering, we underscore the need for radical redesign of production processes. By incorporating Value Chain concepts, we focus management on the need to strengthen value-adding processes while eliminating all processes that do not add value. TQM provides a means for continuous improvement. In synthesizing the concepts within an environmental frame, we have constructed a generic framework for Green Reengineering. Using this framework, corporate management can use environmental impact as an additional performance measure for reengineering programs. Incorporating environmental management into business strategy can be daunting, and the path to corporate environmental social responsibility unclear. Additional work is needed to validate the framework with current case studies and to study environmental corporate social responsibility longitudinally.

\section{REFERENCES}

[1] "McDonalds, Food For Thought," The Economist, August 29, 1992, p 64-66.

[2] "The Challenge of Going Green," Harvard Business Review, July/August 1994, Vol. 72:37-42.

[3] “The Growing Ranks of Enviro-Cops," Nation's Business, June 1994, p 29-32

[4] Arlow, P. and M. J. Gannon, "Social Responsiveness, Corporate Structure and Economic Performance," Academy of Management Review, Vol. 7, 1982, pp. 235-241.

[5] Begley, S., "Buried Alive", Newsweek, 114 November 27, 1989, p 66-76.

[6] Bhat, V. N., "A Blueprint for Green Product Development", IM, March/April 1993, 4-7.

[7] Epstein, M., "What Shareholders Really Want." New York Times, April 28, 1991.

[8] Gupta, M. and K. Sharma, "Environmental Operations Management: An Opportunity for Improvement," Production and Inventory Management Journal, Vol. 37:3, pp. 40-46.

[9] Hall, R., The Soul of the Enterprise, Harper Business Press, 1993, p153-169.

[10] Hammer, M. and J. Champy, Reengineering the Corporation, Harper Collins, 1993 pp. 32-35

[11] Hunt, C. B. and E. R. Auster, "Proactive Environmental Management: Avoiding the Toxic Trap," Sloan Management Review, Vol. 31:2, 1990, pp. 7-18.

\section{ARTICULATE THE GREEN VISION AND GOALS}

Develop Business Vision and Goals

Organize the team

Communicate the motivations

Prioritize green objectives and set stretch targets

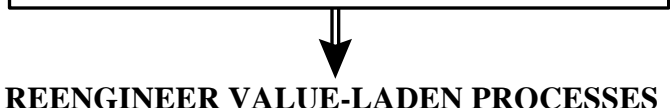

REENGINEER VALUE-LADEN PROCESSES

Identify Processes to Be Reengineered

Identify value adding processes

Understand and measure processes - set baseline

Assess priority of processes

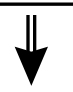

\section{PRIORITIZE ENFIRONMENTAL OPPORTUNITIES}

Identify Green Levers

Identify green opportunities within processes Quantify costs \& benefits of green reengineering

Prioritize opportunities and select project

\section{IMPLEMENT \& MONITOR PROCESSES}

Design and Build Green Prototypes

Implement enterprise and technical components Compare green and financial results with projections

Communicate results and return to Visioning Process

Fig. 2. The Green Reengineering Framework

[12] Johansson, H.J., P. McHugh, A. J. Pendlebury, and W. A. Wheeler III, Business Process Reengineering: Breakpoint Strategies for Market Dominance, London, England: Wiley, 1993

[13] Klassen, R. D. and C. P. McLaughlin, "The Impact of Environmental Management on Firm Performance," Management Science, Vol. 42:8, August 1996, pp. 1199-1214.

[14] Lozada, H. R., Green Based Innovation: Sustainable Development in Product Management, Harpers, 1995, p 179.

[15] Miller, C., "Use of Environmentally Friendly Packaging May Take A While," Marketing News, 24, March 19, 1990, p 18.

[16] Porter, M., Competitive Advantage, New York: Free Press, 1985, 33-61.

[17] Rosewicz, B., "American are Willing to Sacrifice to Reduce Pollution, They Say," The Wall Street Journal, New York, April 20, 1990, A1.

[18] Royson, M. G., Pollution Pays, Pergamon Press, 1979.

[19] Schlossberg, H., "Environmental Concerns Leads Some Consumers to Change Buying Habits," Marketing News, 34, December 24, 1990, p7.

[20] Schmidheiny, S., Changing Course: A Global Business Perspective on Development and the Environment, Cambridge, MA: MIT Press, 1992, pp.60-68.

[21] Smith, E., "Cleaning Up the Coming Cleanup," Businessweek October 16th, 1989 p 96-102.

[22] Stuller, J., "The Politics of Packaging," Across the Board, 27, Jan/Feb 1990, p 40-48. 